\title{
The Socio-Economic and Environmental Impact of Tourism Industry on People of Arba Minch and its Surroundings
}

\author{
Temesgen Woza Wonbera \\ School of Social Science and Humanities, Oda Bultum University, PO box 226, Chiro, Ethiopia:
}

\begin{abstract}
:
Contemporary, the tourism industry in Ethiopia has been progressing from time to time. The sector has become the main sources of foreign earnings for many developing countries. The area, Arbaminch, is one of the tourist destination sites in Ethiopia has been identified to have substantial prospective for tourism development. However, due to the nonappearance of adequate research works in the study area together with the lack of crucial infrastructural facilities affected the development of tourism in the area. So, the foremost purposes of this paper is evaluating and identifying the major challenges for the effectual use of the enormous of tourism resources of the area and stress the prospect for tourism development and indicate possible solution to the problems. Both primary and secondary sources including archives, oral informants and relevant references materials are utilized to bring out the history of tourism in Arbaminch and its surroundings.
\end{abstract}

Keywords: attraction, resources, Tourism development, heritage

DOI: $10.7176 / \mathrm{JTHS} / 40-01$

\section{INTRODUCTION}

Many countries in the world incorporated tourism as one of the main component of their economic development and means of earning. Most analysts concur that tourism is the world's leading and the fastest growing industry (Van Beugen, 2005; Tepelus, 2000; TOI, 2003). Services in general and tourism in particular are increasingly viewed as the best opportunities and the most viable options for the sustainable economic social and environmental developments of the least developed countries (Dawid, 2001). Many scholars and writers argue that tourism industry has significant role in rapid development of a country economy. It has both problems and opportunities. Some of the major positive socio-economic impacts of tourism include economic benefits, crosscultural exchange, creating employment opportunity, conservation of historic sites and improvement of infrastructures. The negative impacts include economic and a negative effect on the host society's culture and moral behavior, the expansion of prostitution, the increase in alcoholism, theft of heritages or the expansion of crime, dependency and distortion of facts and history. It should, however, be born in mind that the type and extent of these impacts depend on the type and intensity of the tourism development as well as the characteristics of the host society.

\section{Methods and Material}

In caring out this study, uniformly qualitative and quantitative research method is being used and the most noteworthy data is sourced by primary data collection method using interviews, surveys, and secondary data utilization literatures collected from books, Journals, Past researches and Electronic websites. Tourism is a very wide sector that demands deep investigations. The author has tried his level best in identifying the multipurpose benefit of tourism to Arbaminch people and it drawbacks equally. In addition to get the desired information, other supply of valuable oral accounts would be consulted. The findings of this work are discussed below through storyline and descriptive approaches. The rapid growth of tourism in Ethiopia in general and in Arbaminch area in particular has both positive and negative impact on the social, economic and cultural, environmental aspect of the peoples. 


\section{Tourism as a Means of Poverty Alleviation}

Several authors assert that the tourism industry has the potential to lift people out of poverty through employment and entrepreneurial opportunities. Because of its multi dimensional importance, the sector is considered as one of the sectors that assist the third world countries to come out from poverty such as African countries .It was obvious that, tourism can benefit the vulnerable people in three main ways. Those are, (1) through direct effect on the poor, such as small tourism enterprise and job opportunities. (2) Through secondary effects, such as earnings from supply chain industries (e.g. food and construction). (3) Through dynamics effects on the economy, such as infrastructural development and entrepreneurships.

The implementation of participatory approach would help to achieve sustainable development of tourism and to secure the equal benefit of peoples. One of these was by creating better opportunities for local people to gain large and more balanced benefits from the industry. However, such opportunities to the people of Arba Minch and its Surrounding areas were not implemented. Since, the success of tourism depends on the active support of the local communities. Thus, the equal share of opportunities to the local communities that tourism provides must be balanced. So, depending on these ideas, the major community of Arbaminch area is not the beneficiary of tourism. This was because, the most beneficiaries were peoples who have the financial capacity to provide service and different facilities for tourists and lack and weak implementation of different plans from the government side that assures the benefits of host communities. Therefore, intervention must make to help local communities to be part of the process of that drive the tourism industry. It is also important that the national and local governments are expected to play a critical role in determining the role of host populations in playing in tourism industry and should secure their benefit from the sector.

\section{Economic Benefits of Tourism}

The tourism industry has great role in creating vast job opportunities for tourist destination peoples. Since, the sector is labor intensive; it provides a wide range of different employment opportunities to host communities. It creates opportunities for many small entrepreneurs and for the development of a wide range of small scale business. It gives more employment opportunities for women's and young people than other industries. Nevertheless, the economic benefit of tourism in Arbaminch areas was not distributed properly. There were different reasons forwarded by my informants. The first reason was the weakness of the regional government in providing and implementing various plan that boost the benefits of host communities. Secondly, lack of awareness of the communities about tourism and the conservation and preservation of tourism resources in most tourist destination areas of Arbaminch. Such problems were not serious, but because of the weakness of the Gamo Gofa Zone Tourism and Culture Department, the problem of awareness became high. However, the department said that, now a day's the department working hardly on awareness creation. The department also said that, it was clear that there was unfair economic benefit from the tourism sector between the peoples of Arbaminch, and also the most benefiter were people who have the financial capacity. To solve unfair distribution of such benefits, the department tried its beast in solving the problems by preparing different job opportunities for host communities in tourist destination areas of the Arbaminch. For example, by providing different facilities such as market areas for some organized peoples of the communities to sell their traditional products for both domestic and foreign tourists. In generally, tourism has the following economic importance; it diversifies the destination economy, increases income regeneration to the resident, increase local government revenue in the form of direct and indirect tax and brings foreign exchange for a country, improves production, increase GDP, crate employment opportunist both skilled and unskilled, encouragement of entrepreneurial activity of local of the local community.

\section{Social Benefits of Tourism}

According to Teshale and Gebranynya Gebru, tourism in general has three broad socio cultural advantages. These are the promotion of cross-cultural understanding, the incentive value of tourism in preserving the local culture and heritage and the fostering of social stability. It also brings more opportunities to upgrade facilities such as outdoor recreation facilities, parks and roads. Besides this, it creates favorite image of the destinations 
that help local pride their belongingness of that society, facilities the process of modernization and provide opportunities of education. Tourism also contributes the renaissance of traditional arts and crafts.

The same is true in Arbaminch. Tourism advocated the area economic development by generating income through entrance fee and it created job opportunity accesses for a number of host peoples. It also played critical role in improving the social well being of Arbaminch people. According to the Gamo Gofa Zone Tourism and Culture Department and informants, the tourism sector in Arbaminch area helped several householders by organizing them to sell their local products for tourists. In general, tourism has the following socio-cultural importance for the people of Arbaminch; Tourism played a significant role in promoting and encouraging better understanding between people of different culture and nationalities, it revive and preserve of the local handicraft industry, it preserves cultural identity of host population, it increased cultural contacts with foreigners, it also created greater tolerance of social differences, it also facilitates educational experience, it created employment opportunity, especially for woman's and young people of the community, such as through organizing younger's and let them giving service in tour guide and finally, it increased the quality of life and living standards and develop language skill.

\section{Environmental Benefits of Tourism}

Like that of economic, cultural and social impact of tourism it has also an impact on environment of Arbaminch areas. Its impact is broadly comprises with two benefits, these are, it protect and enhance the environmental assets of the destination and creates good opportunity to maintain ecotourism. According to Gebranynya Gebru and Agumas Fekadu, Tourism creates a favorable condition to increases investment in environmental infrastructure of the host communities; it encourages education of valve of natural, it can help to promote the establishment of national parks and/or wildlife reserves and it also promotes the preservation of buildings/monuments.

The peoples of Arbaminch areas were one of the people benefiting a lot from the tourism industry. According to informants, tourism has much importance to them especially in securing the environmental ecology of the area. For instance, because of tourism, the area was the owner of Nech Sar National Park and it helped them to preserve their natural resources. In addition, it created good opportunity to show and protect their cultural environment to the rest of world. However, as the owner of the tourism resources of the area, the peoples of Arbaminch and its surrounding areas were not secure their environmental benefits of tourism as such as other tourist destination peoples of Ethiopia. These was because, most of the time, the lion share of the benefits goes to some peoples of the communities such as peoples who has money capacity and organized peoples and institutions. For example, the peoples not gate a desirable benefit from natural gifts such as a fire wood and grass. This was because of weak management of both the Arbaminch town and Nech Sar National Park. Such unfair distribution of benefits led some people to show the revenge on nature. In other word, they express their anger by miss using of nature.

\section{Socio-Cultural, Economical, and Environmental Drawbacks of Tourism Industry on People of Arba Minch and its Surroundings}

At the same time, the tourism industry has a negative impact on the peoples of Arba Minch and its Surroundings. Many authors discussed that the magnitude of the negative impacts of tourism was equal to that of the positive benefits. For instance, Teshale argued that the globally developing of tourism has not only positive impact for tourist distention areas, but it has negative impact on their economic, social, cultural and environmental aspect.

\section{Negative Socio-Cultural Impacts of Tourism}

According to different researchers, besides its positive impacts, the tourism industry has also negative impact in the social and culture issue of the host communities. To mention some, it causes to deterioration of the existing culture and customs (identity loss) of the host community, the intensification of Crime, gambling, drug trafficking, alcoholism, prostitution, and commercialization of culture, religion and arts. 
Since the area of Arbaminch and its surroundings are one of the tourist destination sites in the country, the negative effects of tourism was highly expanding. According to my informants, because of tourism, in some part of the town there was the expansion of prostitution, alcoholism and drug addiction. It also becomes reason for the expansion of Crime and loss of heritages. In addition, some cultures of the community were endangered. For example, because of the influence of tourist culture, the area wearing and feeding styles was changed. In the same case, to earn money, some female communities were engaged in skin trafficking and prostitution. According to Arbaminch municipality, there were 1300 women engaged in prostitution and 500 orphan children's existed in the town and one of the problems for the rapid growth of prostitution was the increasing number of tourists.

\section{Economic Drawbacks of Tourism}

Tourism creates shortage of some commodities in the local area and Inflation will be created. According to Gebranynya Gebru, tourism may create clash with the demand of agriculture land. For instance, Tourist development must demands space; land must be made available for tourist activities such as the foundation of national park or protected areas for different tourism purpose. In these courses, peoples clash with government bodies. We can take such cases in the area of Arbaminch as an example. Because of Nech Sar National Park, a conflict arises between the demands of tourism on the one hand and agriculture on the other. The other negative impact of tourism on economic issues is seasonality problem. Since tourism was characterized by seasonality, it creates seasonal unemployment. For instance, arrivals are high during November to January. Similarly to Gebranynya, Agumas mentioned that, the negative consequence of tourism can also include increment of price on goods and services of tourist destination areas, increment of the cost of construction for various infrastructures, increment of the price of land and house rent and so on.

\section{Environmental Drawbacks of Tourism}

Beside it positive role, tourism has the negative impact on the environment of Arbaminch and its surrounding area., It caused for degradation of the area ecosystems and environments, air and water pollution and become reason for loss of aquatic and marine animals. The construction of accommodation, parks, as well as tourist, airports, and new resort hotel creates pressure on the area environmental ecology. Clearance of existing natural vegetation, Selective introduction of exotic (foreign) plants, leveling would also affect the environment of Arbaminch area. The generation of waste residuals such as sewage, Production of garbage, Atmospheric emission from aircraft on the other hand highly affects on the same level the environment of Arbaminch area. Efforts have been done to minimize the negative impacts of tourism on the environment of Arbaminch by the Gamo Gofa Zone Tourism and Culture Department through awareness creation to host communities, by providing different west managing materials. However, some of informant says that, the most of the work to reduce the negative impacts of tourism on environment merely in the town. The work was not penetrated to rural part of Arbaminch.

\section{Conclusion}

The tourism industry in Ethiopia in general and in Arbaminch area in particular plays great role. However, Because of different problems like shortage trained man power, sufficient tourist facilities, infrastructures and lack of awareness of local people and lack finance to run different programs of the tourism industry of the area, the development of the sector in Arbaminch and its surrounding area was not reached as it was expected. Different attempt has been made to solve those problems in different level of concerning bodies. Nevertheless, the weak performance coupled with strong policy consequences for low development of the industry. Because of the above reason, unfair economic benefit from the tourism sector between the peoples of Arbaminch is common. So, this study attempt to explore those advantages of tourism industry to the people of Arbaminch in general and to those tourist destinations of other parts of the country and it become the prime references for researchers and other interested government bodies like policy makers. 


\section{Acknowledgements}

The accomplishment of this study is come out through the contribution of different people to whom I would like to express my appreciation in Return. I would like to convey my sincerely gratefulness to the following peoples and Institutions who have been engaged in the entire process of this work. First of all many things should go to Mr. Buruk W/Michael for the valuable advice and important correction and comments that they made at every step in the progress of the research work. My special thanks also goes to all my informants, Gamo Goffa Zone Culture, Tourism and Government Communication Affair officials and Arbaminch Nech Sar National Park Bureau officials for their willingness to donate the information during data collection.

\section{References}

Agumas Fekadu. 2012. "The Impact of Tourism on Culture on Tourist Destination Area: A case Study of Hamer People”. A.A.U: MA Thesis, Linguistics and Philosophy.

David Weaver, m. O. (2002). Tourism management. Brisbane: John Wiley and Sons Australia, Ltd.

Gamo Gofa Zone Cultural and Tourism Office. (2007). "The Gamo Gofa Zone Tangible and Non Tangible Heritages". Arbaminch.

Gebranynya Gebru. 2011. "A Study on Socio-Economic Impacts of Tourism in Axum Town, Tigray Regional State, Ethiopia”.A.A.U: MA Thesis, Geography and Environmental Study.

Tepelus, C. M. 2000 Tracking Travel and Tourism, Towards Sustainability Reporting for Tour Operators. The International Institute for Industrial Environmental Economics (IIIEE) Reports 2000:16, Lund University, Sweden.

Teshale Biazen.2010. "Ethiopia as a Tourist Destination, an Exploration of Swedish Tourist Market Demand (Case Study)”. Bleking Institute of Technology: M.A Thesis, Management

Van Beugen, M.C.A. 2005 Sustainability of Dutch Tour Operators. Thesis, the Department of Leisure Sciences, Faculty of Social and Behavioral Sciences, Tilburg University, The Netherlands. 